\title{
Any Correlation Between Prostate Volume and Incidence of Prostate Cancer: A Review of Reported Data for the Last Thirty Years
}

\author{
Justine R Yamashiro (D) \\ Werner TW de Riese (D) \\ Department of Urology, School of \\ Medicine, Texas Tech University Health \\ Sciences Center, Lubbock, TX, USA
}

\begin{abstract}
Purpose: Prostate cancer ( $\mathrm{PCa}$ ) is the most common non-skin cancer in men worldwide and more than $80 \%$ of men with $\mathrm{PCa}$ also have histo-anatomical findings of benign prostate hyperplasia (BPH). It is well documented that $\mathrm{BPH}$ develops in the transition zone (TZ), whereas $80-85 \%$ of PCa originates in the peripheral zone (PZ) of the prostate. Possible causal links between both disease entities are controversially discussed in the current literature. Some studies have reported that larger prostates have a decreased incidence of PCa compared to smaller prostates. The purpose of this systematic review is to comprehensively summarize studies analyzing any association between prostate gland volume and incidence of PCa.
\end{abstract}

Methods: A thorough literature review was performed between 01.01.1990 through 02.28.2020 using PubMed and applying the "PRISMA" guidelines. Inclusion and exclusion criteria were defined.

Results: Our systematic review found 41 articles reporting an inverse (negative) relationship between prostate gland volume and incidence of prostate cancer. Sample sizes ranged from 114 to 6692 patients in these single institutional and multi-institutional studies. Thirty-nine (95\%) of the 41 articles showed a statistically significant inverse relationship. In our search, no study was found showing a positive correlation between BPH size and the incidence of PCa.

Conclusion: To our knowledge, this is the first systematic review on the important clinical question of interaction between prostate size and the incidence of $\mathrm{PCa}$. The results are demonstrating an inverse relationship, and therefore reveal strong evidence that large prostates may be protective of $\mathrm{PCa}$ when compared to smaller prostates.

Keywords: prostate size, benign prostate hyperplasia, inverse relationship

\section{Introduction}

Prostate cancer $(\mathrm{PCa})$ is the most common non-skin cancer in men worldwide. Despite recent progress in diagnosing and treatment of $\mathrm{PCa}$, there are still 1,600,000 cases and 366,000 deaths annually in the United States. ${ }^{1}$ It is well documented in the literature that $80-85 \%$ of $\mathrm{PCa}$ arises from the peripheral zone of the prostate gland, and metastatic PCa is the third-leading cause of cancer-related death. $^{2}$

More than $80 \%$ of men with $\mathrm{PCa}$ also have histological findings of benign prostate hyperplasia $(\mathrm{BPH})$ with or without clinical symptoms. ${ }^{2}$ Both disease entities occur in the same age group (elderly males), have hormone-dependent growth, and respond to antiandrogen therapy. ${ }^{3,4}$ Some clinicians support the
Correspondence: Werner TW de Riese Department of Urology, School of Medicine, Texas Tech University Health Sciences Center, 360I - 4th Street STOP 7260, Lubbock, TX, 79430, USA

Tel + | 806-743-3862

Fax +1 806-743-3030

Email werner.deriese@ttuhsc.edu 
controversial narrative that $\mathrm{BPH}$ is the precursor for $\mathrm{PCa}{ }^{5}$ But other clinicians state that diagnostics and treatment of symptomatic BPH may increase the chance of diagnosing an incidental prostate cancer, and some reports state that large $\mathrm{BPH}$ prostates may be even protective against $\mathrm{PCa}^{3,5,6}$ Some recent studies have reported that larger prostates have a decreased incidence of PCa compared to smaller prostates, but there are no review papers analyzing any relationship across multiple institutions and studies. The purpose of this report is to provide a systematic review, and therefore more insight regarding any association between BPH (prostate gland) volume and the incidence of $\mathrm{PCa}$.

\section{Materials and Methods}

A focused literature search was conducted on the PubMed database according to the Preferred Reporting Items for Systematic Reviews and Meta-analysis (PRISMA) guidelines. ${ }^{7}$ The predefined search terms "prostate cancer" AND "prostate volume" AND "prostate size" were used to identify articles describing any relationship between prostate gland volume and incidence of PCa. The inclusion criteria for the search were as follows: a) articles in English, b) published in the years between January 1st, 1990 through December 31st, 2020, c) cohort studies only in humans, d) data provided for prostate volumes and e) incidence of biopsy proven prostate cancer in the reported cohort. The exclusion criteria were as follows: a) articles not published in English, b) studies not in humans, c) no detailed data on prostate volume provided in relation to the incidence of biopsy proven prostate cancer in the cohort, and d) biopsies in patients after previous treatment for PCa. The extracted data variables were as follows: authors, journal, year of publication, sample size of reported cohort, association between prostate volume and incidence of biopsy-proven $\mathrm{PCa}$, and $\mathrm{p}$-value to assess statistical significance.

The p-value of the statistical analysis results were taken from the respective studies, no additional statistics were performed on the extrapolated data as these listed studies were all peer-reviewed. These p-values were placed on a forest plot to graphically compare the significance of each of the studies' results using Excel (version 2108).

\section{Results}

The literature search identified 41 original articles meeting the inclusion criteria for review. Figure 1 illustrates the search strategy and study selection flowchart according to the PRISMA guidelines. ${ }^{7}$ Table 1 and Figure 2 present the clinically relevant findings from each study. The studies ranged from a sample size of 114 to 6692 patients. There was a mix of single institutional and multi-institutional studies. For instance, Al-Azab et al assessed prostate volumes of 1796 patients using transrectal ultrasound (TRUS) and concluded that "men with a large prostate volume (larger than $72 \mathrm{cc}$ ) had a $20.5 \%$ risk of prostate cancer on biopsies compared to men with the smallest prostate volume (less than $38 \mathrm{cc}$ ) who had $65.8 \%$ risk of cancer" (p-value <0.001). ${ }^{8}$ Karakiewicz et al reported, in a sample size of 1974 patients, the highest positive biopsy rate $(39.6 \%)$ among prostates smaller than $20 \mathrm{cc}$, whereas the lowest positive biopsy rate $(10.1 \%)$ was found in glands between 80-90cc (p-value <0.02). ${ }^{9}$

Thirty-nine of the forty-one articles (95\%) showed a statistically significant inverse (negative) relationship between prostate size and the incidence of $\mathrm{PCa}$ with a p-value of at least $<0.05$ (Table 1), and the Forest plot of all studies (Figure 2) showed a significance level of 0.01. In the PRISMA-guided search no study was found showing a positive correlation between these two clinical parameters.

\section{Discussion}

The inverse relationship between prostate size and the incidence and aggressiveness of PCa has been demonstrated in numerous clinical studies as listed in Table 1. As prostate volume increases, incidence of PCa decreases and patients with larger prostates have also been shown to have a better prognosis. ${ }^{10}$ These findings are rarely challenged in the recent literature and no study in our systematic review demonstrated a positive correlation between prostate volume and incidence of PCa. Al-Khalil et al demonstrated that the incidence of $\mathrm{PCa}$ was reduced by $40 \%$ in larger prostates with a volume $>65 \mathrm{cc}$ when compared to smaller prostates with a volume $<35 \mathrm{cc}$ (p-value $<0.05)$. The study also showed that out of 110 biopsypositive patients with prostates $<35 \mathrm{cc}, 10$ patients had a Gleason score of $\geq 8(9.1 \%)$ and out of 27 biopsypositive patients with prostates $>65 \mathrm{cc}$, only 1 had a Gleason score of $\geq 8(3.7 \%){ }^{10}$

The zones of the prostate gland are divided into the central zone $(\mathrm{CZ})$, transition zone $(\mathrm{TZ})$, peripheral zone (PZ), and anterior fibromuscular stroma. These zones arise from different embryologic origins and are distinguished by their appearance, anatomic landmarks, biologic functions, and susceptibility to pathology (for details see Table 2). ${ }^{11}$ In imaging, TRUS and on MRI, only the PZ 


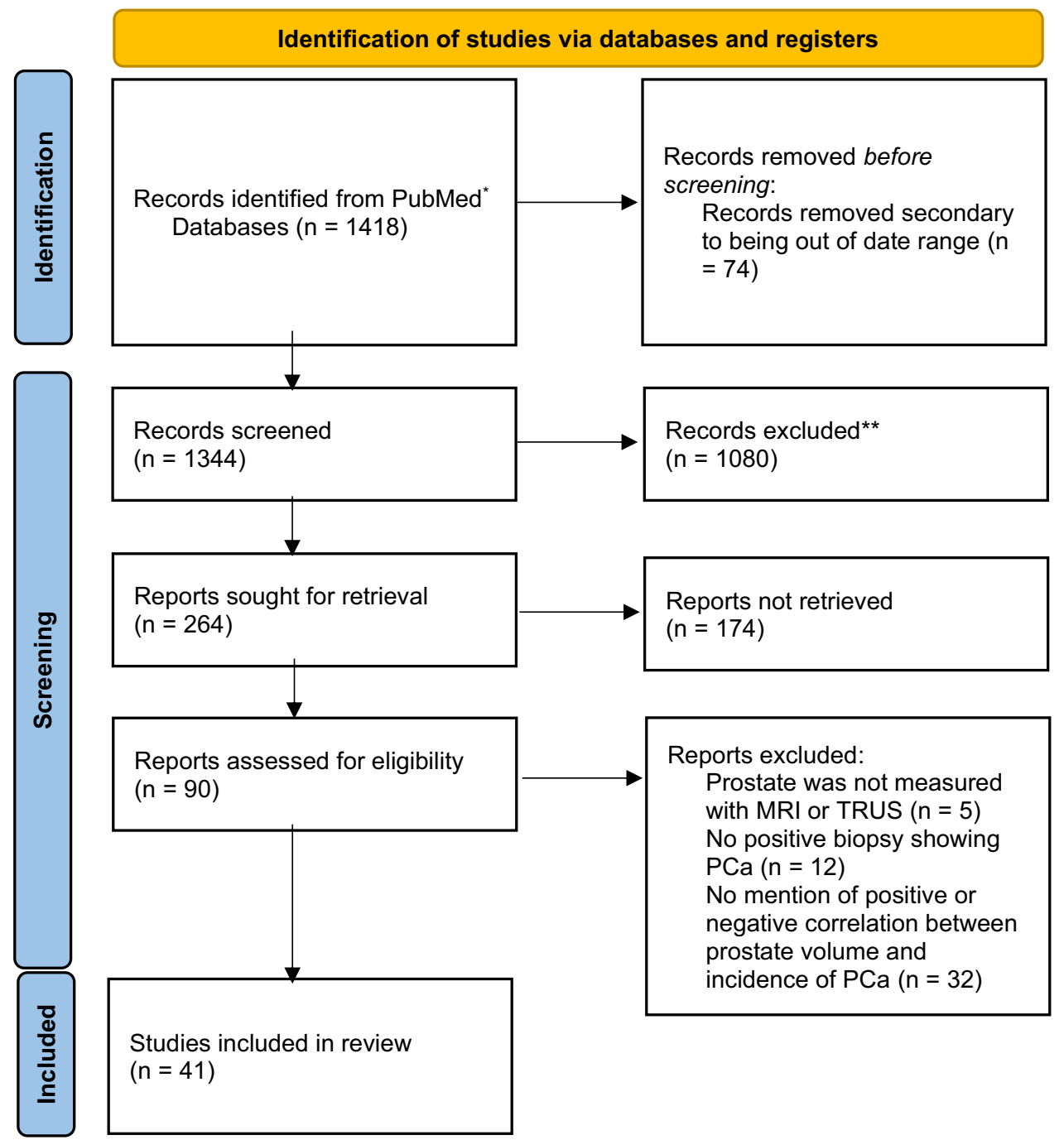

Figure I PRISMA flowchart for literature search and selection of studies.

Notes: *Literature search range was from January 1990-December 2020: "prostate cancer" AND "prostate volume" AND "prostate size". **Records excluded by PubMed automated filter system. Adapted from Liberati A, Altman DG, Tetzlaff J et al. The PRISMA statement for reporting systematic reviews and meta-analyses of studies that evaluate health-care interventions: explanation and elaboration. PLOS MED. 2009;6(7):eI000I007 .

can be well differentiated from the "rest" of the prostate, which is often referred to as the "central gland" by radiologist. The term "central gland" must be distinguished from the term "central zone" which is difficult to isolate on imaging.

It is well documented in anatomical and imaging studies that $\mathrm{BPH}$ originates in the $\mathrm{TZ}$ while $80-85 \%$ of $\mathrm{PCa}$ originates in the PZ. ${ }^{11,12} \mathrm{~A}$ recent review article summarized that the "histo-anatomical changes within the peripheral zone caused by BPH growth lead to significant tissue transformation within the peripheral zone". ${ }^{12}$ This transformation causes thickening of the prostatic capsule secondary to fibrosis which is also called the surgical capsule by urologists due to the distinctive plane between the $\mathrm{TZ}$ and PZ in large BPH prostates which is much less evident in small prostates. This process causes epithelial cell atrophy within the PZ due to direct pressure-related tissue injury and reduced blood flow caused by the expanding $\mathrm{TZ}$ in growing BPH. Due to this process, gland atrophy is seen within the PZ. As $80 \%$ of $\mathrm{PCa}$ originates from the glandular epithelium within the $\mathrm{PZ}$ this supports the hypothesis that these dynamic interactions between the growing $\mathrm{TZ}$ and compressed $\mathrm{PZ}$ explain the decreased incidence of PCa in large BPH prostates. ${ }^{13,14}$ Sellers et al performed multiparametric MRI prostate studies on biopsy naïve patients. This study focused on specific PZ measurements which demonstrated compression of the $\mathrm{PZ}$ in large prostates compared to smaller prostates: Small and mid- 
Table I List of Studies and Relationship Between Prostate Size and Incidence of Prostate Cancer, Respectively

\begin{tabular}{|c|c|c|c|c|c|}
\hline Author et al. & Journal & Year & \# of Pts (n) & $\begin{array}{c}\text { Inverse Correlation } \\
\text { Prostate Size and } \\
\text { Prostate Cancer (Yes/ } \\
\text { No/Ambiguous) }\end{array}$ & p-value ${ }^{a}$ \\
\hline Al-Khalii ${ }^{6}$ & Int Urol Nephrol & 2016 & 448 & Yes & $<0.05$ \\
\hline Al-Khalil ${ }^{10}$ & Res Rep Urol & 2016 & 448 & Yes & $<0.001$ \\
\hline Chang $^{31}$ & Oncotarget & 2017 & 247 & Yes & $<0.0001$ \\
\hline Zheng $^{32}$ & PLOS One & 2019 & 422 & Yes & $<0.001$ \\
\hline Briganti ${ }^{33}$ & Eur J Cancer & 2007 & 3412 & Yes & $<0.001$ \\
\hline Newton ${ }^{34}$ & J Urol & 2009 & 2880 & Yes & $<0.001$ \\
\hline $\mathrm{Nepal}^{35}$ & Turk J Uro & 2020 & 659 & Yes & $<0.001$ \\
\hline Sooriakumaran ${ }^{36}$ & Urol Int & 2011 & 2207 & Yes & $<0.001$ \\
\hline Yoon $^{37}$ & Urol J & 2011 & 474 & Yes & $<0.05$ \\
\hline Fang $^{38}$ & Biomed Res Int & 2015 & 345 & Yes & $<0.001$ \\
\hline Yadav $^{39}$ & J Endourol & 2009 & 700 & Yes & 0.001 \\
\hline Al-Azab ${ }^{8}$ & J Urol & 2007 & 1796 & Yes & $<0.001$ \\
\hline Elliot $^{20}$ & Clin Cancer Res & 2009 & 1304 & Yes & $<0.001$ \\
\hline $\mathrm{Haas}^{40}$ & Urol Int & 2017 & 148 & Yes & 0.004 \\
\hline Colleselli $^{41}$ & BJU Int & 2007 & 345 & Yes & $<0.05$ \\
\hline Sfakianos ${ }^{42}$ & BJU Int & 2010 & 3040 & Yes & 0.01 \\
\hline Novara $^{43}$ & BJU Int & 2009 & 143 & Yes & 0.002 \\
\hline Ung $^{44}$ & J Urol & 2003 & 750 & Yes & 0.0074 \\
\hline Kobayashi ${ }^{45}$ & Int J Urol & 2005 & 154 & Yes & $<0.0001$ \\
\hline Uzzo ${ }^{46}$ & Urology & 1995 & 1021 & Yes & $<0.01$ \\
\hline Hong $^{47}$ & Urology & 2014 & 1756 & Yes & 0.032 \\
\hline Rundle $^{48}$ & Prostate & 2017 & 6692 & Yes & b \\
\hline$W^{49}$ & Asian J Androl & 2014 & 1486 & Yes & $<0.05$ \\
\hline Porcaro ${ }^{50}$ & Urol Int & 2015 & 251 & Yes & $<0.0001$ \\
\hline Porcaro ${ }^{51}$ & Urol Int & 2017 & 596 & Yes & $<0.0001$ \\
\hline Fowke ${ }^{52}$ & Cancer Causes Control & 2007 & 286 & Yes & $<0.01$ \\
\hline Eskicorapci ${ }^{53}$ & J Urol & 2005 & 503 & Yes & $<0.001$ \\
\hline Werahera $^{54}$ & Int J Clin Exp Pathol & 2012 & 114 & Yes & b \\
\hline Bruno $^{55}$ & J Urol & 2007 & 296 & Yes & $<0.001$ \\
\hline Kulkarni ${ }^{56}$ & J Urol & 2006 & 369 & Yes & 0.008 \\
\hline Karakiewicz ${ }^{9}$ & Urology & 1997 & 1974 & Yes & $<0.001$ \\
\hline $\mathrm{Mir}^{57}$ & BJU Int & 2008 & 390 & Yes & 0.001 \\
\hline $\mathrm{Kim}^{58}$ & Yonsei Med J & 2013 & 1035 & Yes & $<0.001$ \\
\hline Ankerst ${ }^{59}$ & J Urol & 2013 & 1094 & Yes & $<0.0001$ \\
\hline Tanaka $^{60}$ & Hinyokika Kiyo & 2007 & 210 & Yes & $<0.001$ \\
\hline Tang $^{61}$ & Asian J Androl & 2013 & 261 & Yes & $<0.001$ \\
\hline Aganovic $^{62}$ & Med Arh & 2012 & 323 & Yes & $<0.05$ \\
\hline Kwon ${ }^{63}$ & BJU Int & 2010 & 579 & Yes & 0.025 \\
\hline Gohji $^{64}$ & Cancer & 1997 & 287 & Yes & 0.0009 \\
\hline Egawa $^{65}$ & Int J Urol & 1999 & 706 & Yes & $<0.0001$ \\
\hline Rietbergen ${ }^{66}$ & Urology & 1998 & 1202 & Yes & $<0.0001$ \\
\hline
\end{tabular}

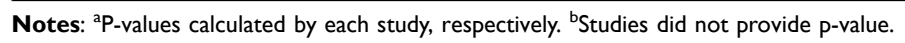

size prostates had a huge range of PZ thickness whereas large prostates with a total volume around $90 \mathrm{~mL}$ or above showed a noticeable drop in PZ thickness suggesting the $\mathrm{PZ}$ can resist pressure from the $\mathrm{TZ}$ growth to a certain point only. ${ }^{15}$
This inverse relationship may also explain the results of the Prostate Cancer Prevention Trial, where almost 19,000 patients received continuous Finasteride medication. The treatment arm showed a more than a twofold increase in high grade aggressive PCa. Finasteride is 

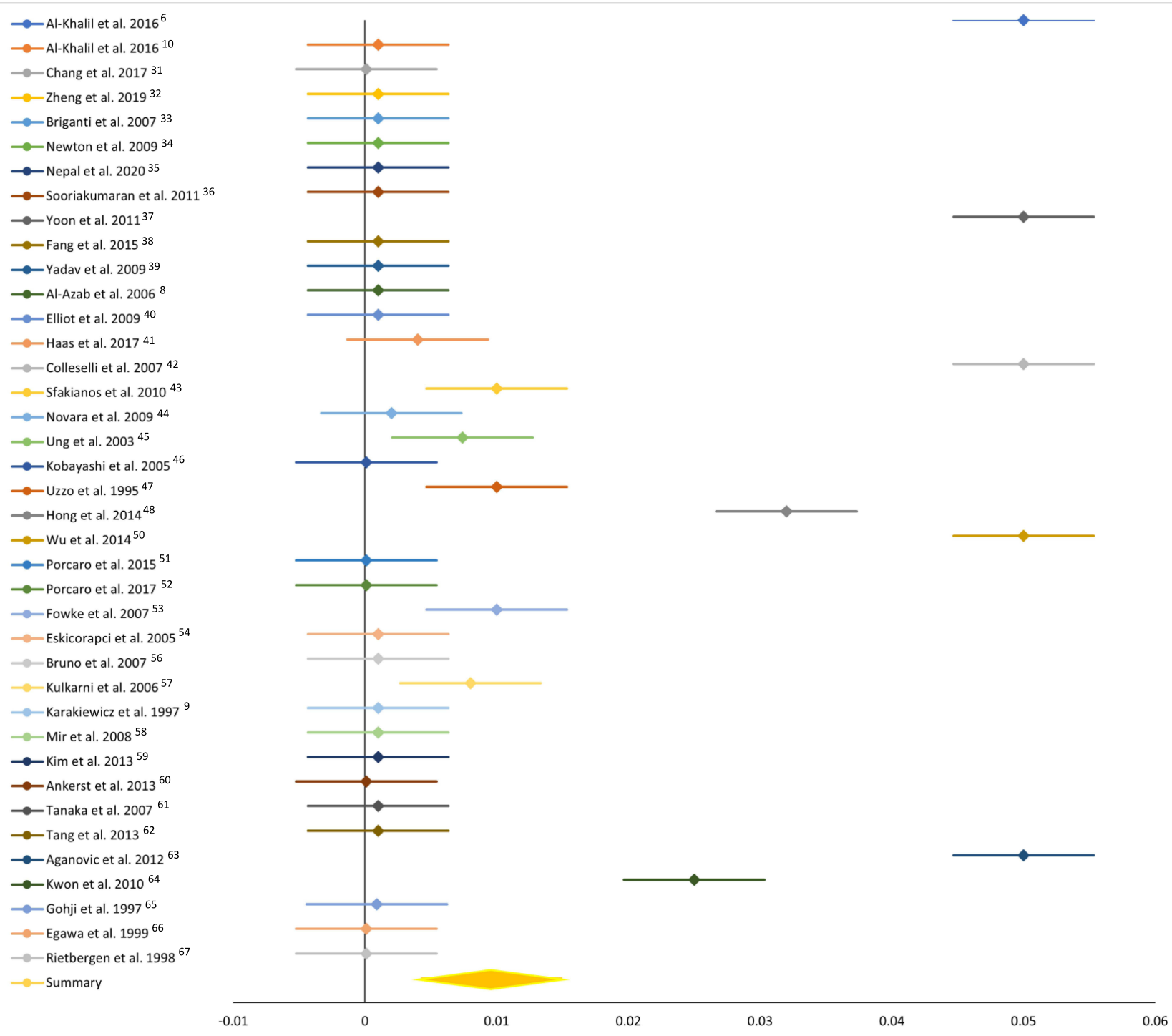

Figure 2 Forest plot for $\mathrm{p}$-value of reviewed studies.

known to affect and reduce the growth of the $T Z$, thus giving the glandular epithelium of the $\mathrm{PZ}$ more room within the prostate to grow and expand. ${ }^{16}$ This clinical observation has been confirmed by Lorenzo et al in mathematical simulation studies analyzing the controversial effects of $5 \alpha$ reductase inhibitors (5ARIs), and found that "the shrinkage of the prostate induced by 5ARIs reduced the hydrostatic stress that had accumulated over years of BPH in prostatic tissue, which led to a mechanical state that favored the development of $\mathrm{PCa} "{ }^{17}$

Many studies listed in Table 1 have reported that prostate volume is one of the most significant predictive factors for the detection of prostate cancer both in univariate and multivariate analysis. Historically, prostate-specific

Table 2 Summary of Histologic Composition and Embryologic Origins of the Different Zones of the Prostate Gland

\begin{tabular}{|l|c|c|c|}
\hline & Central Zone (CZ) & Transition Zone (TZ) & Peripheral Zone (PZ) \\
\hline Volume of normal prostate (\%) & 25 & 5 & 70 \\
Embryologic origin & Wolffian duct & Urogenital sinus & Urogenital sinus \\
Origin of prostatic adenocarcinoma (\%) & 5 & $10-15$ & $80-85$ \\
Benign prostatic hyperplasia (\%) & - & 100 & - \\
\hline
\end{tabular}


antigen (PSA) alone has not proven to be a good diagnostic tool in detecting $\mathrm{PCa}$ but combining or adjusting it with gland volume, prostate-specific antigen density (PSAD), has improved its diagnostic value. ${ }^{18,19}$ Elliott et al demonstrated that PSA performance was significantly better in men with smaller prostates at detecting both low-grade and high-grade $\mathrm{PCa}^{20} \mathrm{Al}-\mathrm{Azab}$ et al suggested that a smaller prostate volume may be the strongest predictor of cancer detection in the PSA range of 2.0 to $9.0 \mathrm{ng} / \mathrm{mL}$, and that adjusting for the patient's prostate volume may help with earlier detection and decrease the need for repeated prostate biopsies. ${ }^{8}$ Previous studies have shown the amount of $\mathrm{BPH}$, and not cancer, is the major factor responsible for the elevation of PSA. However, elevated PSA is the reason for many patients with large prostates to undergo biopsies which are often unnecessary and only lead to overdiagnosis and subsequent overtreatment. ${ }^{21}$ PSAD performance in detecting PCa is affected by prostate volume. The predictive value of PSAD in detecting PCa is higher in smalland medium-sized prostates compared to larger glands. Therefore, many clinical researchers and investigators have recommended that clinicians should counsel patients with large prostates and elevated PSA to consider conservative management such as sequential PSA measurements and not to proceed with biopsies. ${ }^{22,23}$

As outlined in this systemic review, many recent, statistically significant and powerful studies are confirming that BPH may be protective against prostatic cancer supporting the proposed mathematical model by Lorenzo et al that growth of the TZ due to BPH causes increased hydrostatic pressure and compresses the $\mathrm{PZ}$ (where $80-85 \%$ of PCa originates). As mentioned earlier, this histoanatomical process leads to fibrosis and glandular atrophy of the PZ, and thus likely lowers the risk of clinically significant $\mathrm{PCa}^{24}$ This hypothesis is well illustrated by the histo-anatomical study of Guzman et al in showing a decrease in gland density and increase in tissue fibrosis within the PZ in larger prostates when compared to smaller prostates (see Figure $3 \mathrm{~A}$ and $\mathrm{B}$ ). ${ }^{25}$

We are aware of some limitations as this systematic review includes a relatively small number of articles that met the inclusion criteria. Furthermore, the selected studies, although statistically significant, carried large heterogeneity. When reviewing the histo-anatomical studies, the anatomical reconstruction of the prostate by histological specimen slides can be challenging. Gross examination techniques vary greatly among pathologists, with some using coronal cuts, while others use sagittal or transverse cuts, leading to differences in the orientation of the different portions of the prostate specimen. Due to the nature of the prostate, localizing the precise boundaries between the different zones by imaging can be challenging and operator-dependent (ie, TRUS). This is much less an issue with MRI. Another limitation is the variability in biopsy protocol. Sextant and extended needle biopsies have been shown to yield different diagnostic power. Some studies have suggested increasing the number of biopsies for larger prostates may improve the detection of PCa. However, studies have proven that past a certain gland
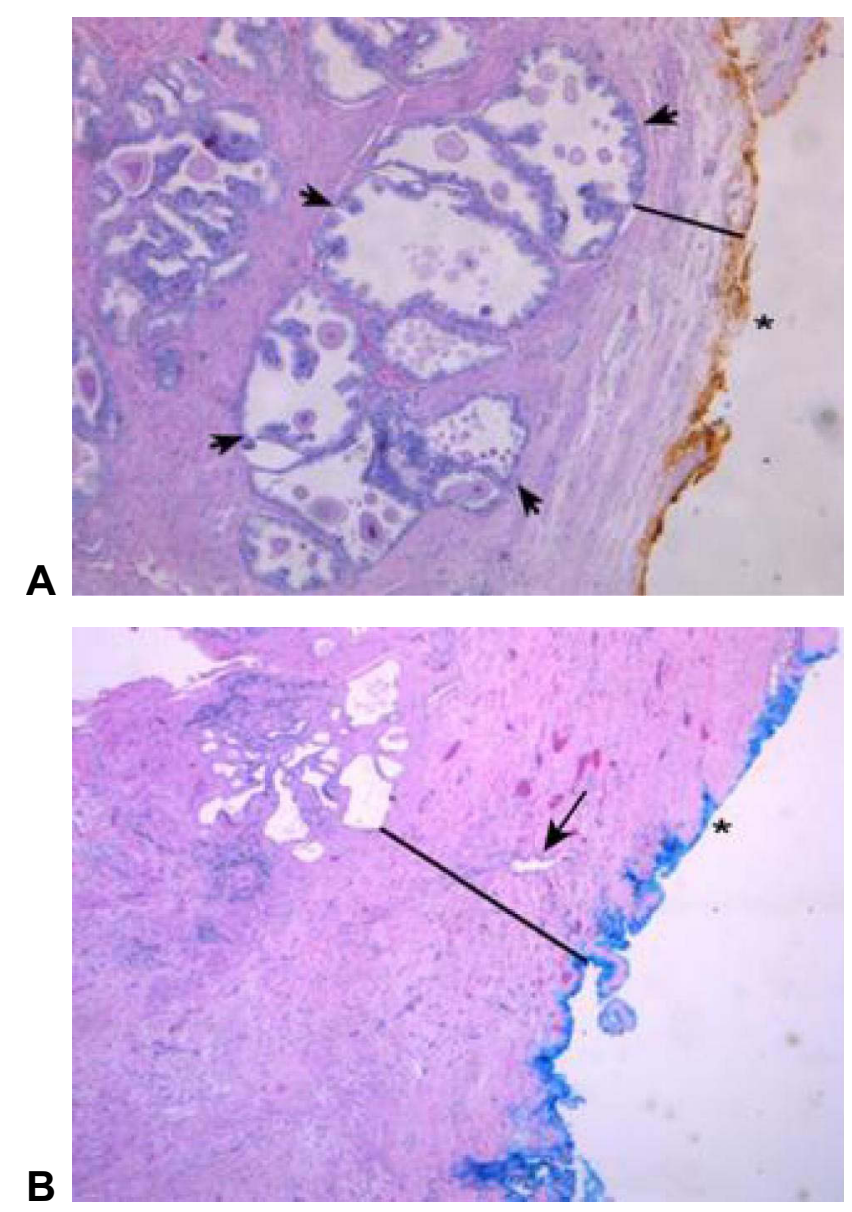

Figure $3 \mathrm{H} \& \mathrm{E}$-stained slides of different sized prostate specimens at $50 \times$ magnification: (A) Small Prostate Specimen (24 g). The external, posterior margin is inked and marked with an asterisk*. A decent number of hyperplastic glands (as indicated by arrows) are present and easily visible in the peripheral zone (PZ) close to the thin capsule (black line). Reproduced with permission from Dove Medical Press Limited, Guzman JA, Sharma P, Smith LA et al. Histological changes of the peripheral zone in small and large prostates and possible clinical implications. Res Rep Urol. 2019;11:77-81. ${ }^{25}$ (B) Large Prostate Specimen (100 g). The external, posterior margin is also inked and marked with an asterisk*. The arrow is indicating an atrophic gland within the extended fibrotic layer/ surgical capsule (black line). This capsule is much thicker in comparison to Figure $2 \mathrm{~A}$, and no hyperplastic glands are present. Reproduced with permission from Dove Medical Press Limited, Guzman JA, Sharma P, Smith LA et al. Histological changes of the peripheral zone in small and large prostates and possible clinical implications. Res Rep Urol. 2019;1 1:77-81. ${ }^{25}$ 
volume the detection rate of $\mathrm{PCa}$ differs minimally between number of biopsies. ${ }^{26,27}$ Furthermore, most of the studies listed in our review were cross-sectional and observational studies which can cause bias in different categories and are difficult to further investigate. Therefore, additional bias assessment on these individual studies were not performed. In this context publication bias should also be mentioned as our review was limited to the PubMed database and the expertise of the authors involved.

Even when considering the limitations mentioned above, this systematic review of clinical studies within the last 30 years strongly supports the hypothesis of protective benefits of BPH against development and progression of clinically significant PCa. With increased use of multiparametric MRI of the prostate in the diagnostic and management of PCa, future studies will likely further elucidate this relationship, in particular because MRI/Ultrasound Fusion biopsies allow increased precision in the diagnosis of clinically significant PCa. ${ }^{28,29}$ This will likely decrease the problem of sampling error experienced with systematic TRUS prostatic biopsy that tends to be more prevalent in larger (BPH associated) prostates. ${ }^{30}$ As MRI technology and its use in the diagnosis of PCa becomes more accessible, future studies will rectify and decrease the impact of sampling error bias associated with this hypothesis. If the described disease process of BPH-induced atrophy of the $\mathrm{PZ}$ glandular tissue and its subsequent protective potential against $\mathrm{PCa}$ is confirmed through future research and studies, it will have important clinical implications related to the diagnosis and treatment of $\mathrm{BPH}$ and $\mathrm{PCa}$.

\section{Conclusion}

This systematic review using the PRISMA guidelines studies the association of BPH (prostate) size and the incidence of PCa. Ninety-five percent (39/41) of the reviewed clinical studies show an inverse correlation between these two clinical parameters. Thus, there is increased evidence supporting the hypothesis that $\mathrm{BPH}$ size may be protective of PCa. This review and the outlined discussion should encourage further studies in exploring the relationship between prostate volume and incidence and aggressiveness of PCa to better understand this phenomenon. If the outlined hypothesis of the dynamic interactions between the different prostatic zones in a growing prostate is correct, it will have relevant clinical implications on future diagnosis and treatment of BPH and PCa.

\section{Funding}

The authors received no financial support for the research, authorship, and/or publication of this article.

\section{Disclosure}

The authors report no conflicts of interest in this work.

\section{References}

1. Wang G, Zhao D, Spring DJ, et al. Genetics and biology of prostate cancer. Genes Dev. 2018;32(17-18):1105-1140. doi:10.1101/ gad.315739.118

2. Liu FC, Hua KC, Lin JR, et al. Prostate resected weight and postoperative prostate cancer incidence after transurethral resection of the prostate. Medicine (Baltimore). 2019;98(3):e13897. doi:10.1097/ MD.0000000000013897

3. Guess HA. Benign prostatic hyperplasia and prostate cancer. Epidemiol Rev. 2001;23:152-158. doi:10.1093/oxfordjournals.epirev.a000782

4. Bostwick DG, Cooner WH, Denis L, et al. The association of benign prostatic hyperplasia and cancer of the prostate. Cancer. 1992;70(1 Suppl):291-301.

5. Ørsted DD, Bojesen SE. The link between benign prostatic hyperplasia and prostate cancer. Nat Rev Urol. 2013;10(1):49-54. doi:10.1038/nrurol.2012.192

6. Al-Khalil S, Boothe D, Durdin T, et al. Interactions between benign prostatic hyperplasia $(\mathrm{BPH})$ and prostate cancer in large prostates: a retrospective date review. Int Urol Nephrol. 2016;48(1):91-97. doi:10.1007/s11255-015-1146-2

7. Liberati A, Altman DG, Tetzlaff J, et al. The PRISMA statement for reporting systematic reviews and meta-analyses of studies that evaluate health care interventions: explanation and elaboration. PLos Med. 2009;6(7):e1000100. doi:10.1371/journal.pmed.1000100

8. Al-Azab R, Toi A, Lockwood G, et al. Prostate volume is strongest predictor of cancer diagnosis at transrectal ultrasound-guided prostate biopsy with prostate-specific antigen values between 2.0 and $9.0 \mathrm{ng} / \mathrm{mL}$. Urology. 2007;69(1):103-107. doi:10.1016/j.urology.2006.09.041

9. Karakiewicz PI, Bazinet M, Aprikian AG, et al. Outcome of sextant biopsy according to gland volume. Urology. 1997;49(1):55-59. doi:10.1016/S0090-4295(96)00360-3

10. Al-Khalil S, Ibilibor C, Cammack JT, et al. Association of prostate volume with incidence and aggressiveness of prostate cancer. Res Rep Urol. 2016;8:201-205.

11. Bhavsar A, Verma S. Anatomic imaging of the prostate. Biomed Res Int. 2014;2014:728539. doi:10.1155/2014/728539

12. Holder K, Galvan B, Sakya J, et al. Anatomical changes of the peripheral zone depending on benign prostatic hyperplasia size and their potential clinical implications: a review for clinicians. Urol Pract. 2021;8(2):259-263. doi:10.1097/UPJ.0000000000000201

13. Weaver PE, Smith LA, Sharma P, et al. Quantitative measurements of prostate capsule and gland density and their correlation to prostate size: possible clinical implications in prostate cancer. Int Urol Nephrol. 2020;52(10):1829-1837. doi:10.1007/s11255-020-02527-6

14. Marks LS, Roehrborn CG, Wolford E, et al. The effect of dutasteride on the peripheral and transition zones of the prostate and the value of the transition zone index in predicting treatment response. $J$ Urol. 2007;177(4):1408-1413. doi:10.1016/j.juro.2006.11.095

15. Sellers J, Wagstaff RG, Helo N, et al. Quantitative measurements of prostatic zones by MRI and their dependence on prostate size: possible clinical implications in prostate cancer. Ther Adv Urol. 2021;13:1-9. doi:10.1177/17562872211000852

16. Tarle M, Spajic B, Kraljic I, et al. Continuous finasteride therapy for benign prostate hypertrophy upgrades both neuroendocrine differentiation and aggressive prostate cancer. Anticancer Res. 2009;29 (5):1797-1801. 
17. Lorenzo G, Hughes TJR, Reali A, et al. A numerical simulation study of the dual role of $5 \alpha$-reductase inhibitors on tumor growth in prostates enlarged by benign prostatic hyperplasia via stress relaxation and apoptosis upregulation. Comput Methods Appl Mech Eng. 2020;362:112843. doi:10.1016/j.cma.2020.112843

18. Dunn MW. Prostate Cancer Screening. Semin Oncol Nurs. 2017;33 (2):156-164. doi:10.1016/j.soncn.2017.02.003

19. Yu HJ, Lai MK. The usefulness of prostate-specific antigen (PSA) density in patients with intermediate serum PSA level in a country with low incidence of prostate cancer. Urology. 1998;51(5):125-130. doi:10.1016/S0090-4295(98)00066-1

20. Elliott CS, Shinghal R, Presti JC. The influence of prostate volume on prostate-specific antigen performance: implications for the prostate cancer prevention trial outcomes. Clin Cancer Res. 2009;15 (14):4694-4699. doi:10.1158/1078-0432.CCR-08-2277

21. Alberts AR, Schoots IG, Roobol MJ. Prostate-specific antigen-based prostate cancer screening: past and future. Int J Urol. 2015;22 (6):524-532. doi:10.1111/iju.12750

22. Omri N, Kamil M, Alexander K, et al. Association between PSA density and pathologically significant prostate cancer: the impact of prostate volume. Prostate. 2020;80(16):1444-1449. doi:10.1002/ pros. 24078

23. Yusim I, Krenawi M, Mazor E, et al. The use of prostate specific antigen density to predict clinically significant prostate cancer. Sci Rep. 2020;10(1):20015. doi:10.1038/s41598-020-76786-9

24. Lorenzo G, Hughes TJR, Dominguez-Frojan P, et al. Computer simulations suggest that prostate enlargement due to benign prostatic hyperplasia mechanically impedes prostate cancer growth. Proc Natl Acad Sci U S A. 2019;116(4):1152-1161. doi:10.1073/pnas.1815735116

25. Guzman JA, Sharma P, Smith LA, et al. Histological changes of the peripheral zone in small and large prostates and possible clinical implications. Res Rep Urol. 2019;11:77-81.

26. Chen Y, Jiang X, Liu R, et al. The specific choice of transrectal ultrasound-guided prostate biopsy scheme based on prostate specific antigen and prostate specific antigen density. Med Sci Monit. 2019;25:6230-6235. doi:10.12659/MSM.915826

27. Inahara $M$, Suzuki H, Kojima S, et al. Improved prostate cancer detection using systematic 14-core biopsy for large prostate glands with normal digital rectal examination findings. Urology. 2006;68 (4):815-819. doi:10.1016/j.urology.2006.05.010

28. Pepe P, Garufi A, Priolo GD, et al. Multiparametric MRI/TRUS fusion prostate biopsy: advantages of a transperineal approach. Anticancer Res. 2017;37(6):3291-3294.

29. Das CJ, Razik A, Sharma S, et al. Prostate biopsy: when and how to perform. Clin Radiol. 2019;74(11):853-864. doi:10.1016/j. crad.2019.03.016

30. Schoenfield L, Jones JS, Zippe CD, et al. The incidence of high-grade prostatic intraepithelial neoplasia and atypical glands suspicious for carcinoma on first-time saturation needle biopsy, and the subsequent risk of cancer. BJU Int. 2007;99(4):770-774. doi:10.1111/j.1464410X.2006.06728.x

31. Chang Y, Chen R, Yang Q, et al. Peripheral zone volume ratio (PZ-ratio) is relevant with biopsy results and can increase the accuracy of current diagnostic modality. Oncotarget. 2017;8 (21):34836-34843. doi:10.18632/oncotarget.16753

32. Zheng S, Jiang S, Chen Z, et al. The roles of MRI-based prostate volume and associated zone-adjusted prostate-specific antigen concentrations in predicting prostate cancer and high-risk prostate cancer. PLoS One. 2019;14(11):e0218645. doi:10.1371/journal. pone. 0218645

33. Briganti A, Chun FK, Suardi N, et al. Prostate volume and adverse prostate cancer features: fact not artifact. Eur J Cancer. 2007;43 (18):2669-2677. doi:10.1016/j.ejca.2007.09.022

34. Newton MR, Phillips S, Chang SS, et al. Smaller prostate size predicts high grade prostate cancer at final pathology. $J$ Urol. 2010;184(3):930-937. doi:10.1016/j.juro.2010.04.082
35. Nepal SP, Nakasato T, Ogawa Y, et al. Prostate cancer detection rate and Gleason score in relation to prostate volume as assessed by magnetic resonance imaging cognitive biopsy and standard biopsy. Turk J Urol. 2020;46(6):449-454. doi:10.5152/tud.2020.20248

36. Sooriakumaran P, Srivastava A, Bhagat D, et al. Prostate volume and its correlation with histopathological outcomes in prostate cancer. Urol Int. 2011;86(2):152-155. doi:10.1159/000322361

37. Yoon BI, Shin TS, Cho HJ, et al. Is it effective to perform two more prostate biopsies according to prostate-specific antigen level and prostate volume in detecting prostate cancer? Prospective study of 10-core and 12-core prostate biopsy. Urol J. 2012;9(2):491-497.

38. Fang D, Ren D, Zhao C, et al. Prevalence and risk factors of prostate cancer in Chinese men with PSA 4-10 ng/mL who underwent TRUS-guided prostate biopsy: the utilization of PAMD score. Biomed Res Int. 2015;2015:596797. doi:10.1155/2015/596797

39. Yadav R, Tu JJ, Jhaveri J, et al. Prostate volume and the incidence of extraprostatic extension: is there a relation? J Endourol. 2009;23 (3):383-386. doi:10.1089/end.2008.0247

40. Haas M, Günzel K, Miller K, et al. Is the ellipsoid formula the new standard for 3-tesla MRI prostate volume calculation without endorectal coil? Urol Int. 2017;98(1):49-53. doi:10.1159/000448593

41. Colleselli D, Bektic J, Schaefer G, et al. The influence of prostate volume on prostate cancer detection using a combined approach of contrast-enhanced ultrasonography-targeted and systematic grey-scale biopsy. BJU Int. 2007;100(6):1264-1267. doi:10.1111/ j.1464-410X.2007.07174.x

42. Sfakianos JP, Thorner DA, Dovirak O, et al. Optimizing prostate cancer detection during biopsy by standardizing the amount of tissue examined per core. BJU Int. 2011;108(10):1578-1581. doi:10.1111/ j.1464-410X.2011.10239.x

43. Novara G, Boscolo-Berto R, Lamon C, et al. Detection rate and factors predictive the presence of prostate cancer in patients undergoing ultrasonography-guided transperineal saturation biopsies of the prostate. BJU Int. 2010;105(9):1242-1246. doi:10.1111/j.1464410X.2009.08954.x

44. Ung JO, San Francisco IF, Regan MM, et al. The relationship of prostate gland volume to extended needle biopsy on prostate cancer detection. J Urol. 2003;169(1):130-135. doi:10.1016/S0022-5347(05)64052-9

45. Kobayashi T, Mitsumori K, Kawahara T, et al. Prostate gland volume is a strong predictor of biopsy results in men 70 years or older with prostate-specific antigen levels of $2.0-10.0 \mathrm{ng} / \mathrm{mL}$. Int $J$ Urol. 2005;12(11):969-975. doi:10.1111/j.1442-2042.2005.01189.x

46. Uzzo RG, Wei JT, Waldbaum RS, et al. The influence of prostate size on cancer detection. Urology. 1995;46(6):831-836. doi:10.1016/ S0090-4295(99)80353-7

47. Hong SK, Poon BY, Sjoberg DD, et al. Prostate size and adverse pathologic features in men undergoing radical prostatectomy. Urology. 2014;84(1):153-157. doi:10.1016/j.urology.2014.04.006

48. Rundle A, Wang Y, Sadasivan S, et al. Larger men have larger prostates: detection bias in epidemiologic studies of obesity and prostate cancer risk. Prostate. 2017;77(9):949-954. doi:10.1002/pros.23350

49. Wu YS, Na R, Xu JF, et al. The influence of prostate volume on cancer detection in the Chinese population. Asian J Androl. 2014;16 (3):482-486. doi:10.4103/1008-682X.125905

50. Porcaro AB, Novella G, Molinari A, et al. Prostate volume index and chronic inflammation of the prostate type IV with respect to the risk of prostate cancer. Urol Int. 2015;94(3):270-285. doi:10.1159/ 000362176

51. Porcaro AB, Novella G, Cacciamani G, et al. Prostate volume index associates with a decreased risk of prostate cancer: results of a large cohort of patients elected to a first biopsy set. Urol Int. 2017;98 (1):22-27. doi:10.1159/000447432

52. Fowke JH, Motley SS, Wills M, et al. Prostate volume modifies the association between obesity and prostate cancer or high-grade prostatic intraepithelial neoplasia. Cancer Causes Control. 2007;18 (4):375-384. doi:10.1007/s10552-007-0119-x 
53. Eskicorapci SY, Guliyev F, Akdogan B, et al. Individualization of the biopsy protocol according to the prostate gland volume for prostate cancer detection. J Urol. 2005;173(5):1536-1540. doi:10.1097/01. ju.0000154242.60413.3d

54. Werahera PN, Sullivan K, La Rosa FG, et al. Optimization of prostate cancer diagnosis by increasing the number of core biopsies based on gland volume. Int J Clin Exp Pathol. 2012;5(9):892-899.

55. Bruno JJ, Armenakas NA, Fracchia JA. Influence of prostate volume and percent free prostate specific antigen on prostate cancer detection in men with a total prostate specific antigen of 2.6 to $10.0 \mathrm{ng} / \mathrm{mL}$. J Urol. 2007;177(5):1741-1744. doi:10.1016/j.juro.2007.01.067

56. Kulkarni GS, Al-Azab R, Lockwood G, et al. Evidence for a biopsy derived grade artifact among larger prostate glands. J Urol. 2006;175 (2):505-509. doi:10.1016/S0022-5347(05)00236-3

57. Mir MC, Planas J, Raventos CX, et al. Is there a relationship between prostate volume and Gleason score? BJU Int. 2008;102(5):563-565. doi:10.1111/j.1464-410X.2008.07696.x

58. Kim YM, Park S, Kim J, et al. Role of prostate volume in the early detection of prostate cancer in a cohort with slowly increasing prostate specific antigen. Yonsei Med J. 2013;54(5):1202-1206. doi:10.3349/ymj.2013.54.5.1202

59. Ankerst DP, Till C, Boeck A, et al. The impact of prostate volume, number of biopsy cores and American Urological Association symptom score on the sensitivity of cancer detection using the Prostate Cancer Prevention Trial risk calculator. J Urol. 2013;190(1):70-76. doi:10.1016/j.juro.2012.12.108

60. Tanaka N, Fujimoto K, Yoshikawa M, et al. Prostatic volume and volume-adjusted prostate-specific antigen as predictive parameters for T1c prostate cancer. Hinyokika Kiyo. 2007;53(7):459-465.
61. Tang $\mathrm{P}$, Jin XL, Uhlman M, et al. Prostate volume as an independent predictor of prostate cancer in men with PSA of 10-50 ng $\mathrm{mL}(-1)$. Asian J Androl. 2013;15(3):409-412. doi:10.1038/aja.2013.11

62. Aganovic D, Prcic A, Kulovac B, et al. Influence of the prostate volume, prostate specific antigen density and number of biopsy samples on prostate cancer detection. Med Arh. 2012;66(1):41-44. doi:10.5455/medarh.2012.66.41-44

63. Kwon T, Jeong IG, You D, et al. Effect of prostate size on pathological outcome and biochemical recurrence after radical prostatectomy for prostate cancer: is it correlated with serum testosterone level? BJU Int. 2010;106(5):633-638. doi:10.1111/j.1464-410X.200 9.09182.x

64. Gohji K, Nomi M, Egawa S, et al. Detection of prostate carcinoma using prostate specific antigen, its density, and the density of the transition zone in Japanese men with intermediate serum prostate specific antigen concentrations. Cancer. 1997;79(10):1969-1976. doi:10.1002/(SICI)1097-0142(19970515)79:10<1969::AIDCNCR19>3.0.CO;2-T

65. Egawa S, Suyama K, Takashima R, et al. Prospective evaluation of prostate cancer detection by prostate-specific antigen-related parameters. Int J Urol. 1999;6(10):493-501. doi:10.1046/j.14422042.1999.00098.x

66. Rietbergen JB, Kranse R, Hoedemaeker RF, et al. Comparison of prostate-specific antigen corrected for total prostate volume and transition zone volume in a population-based screening study. Urology. 1998;52(2):237-246. doi:10.1016/S0090-4295(98)00138-1
Research and Reports in Urology

\section{Publish your work in this journal}

Research and Reports in Urology is an international, peer-reviewed, open access journal publishing original research, reports, editorials, reviews and commentaries on all aspects of adult and pediatric urology in the clinic and laboratory including the following topics: Pathology, pathophysiology of urological disease; Investigation and treatment of urological disease; Pharmacology of drugs used for the treatment of urological disease. The manuscript management system is completely online and includes a very quick and fair peer-review system, which is all easy to use. Visit http://www.dovepress.com/ testimonials.php to read real quotes from published authors. 